\title{
The Operational and Economic Impact of a Neurovascular Unit in an Acute Care Academic Hospital
}

\author{
Eva Appel, Shoshana Hahn-Goldberg, Eric Chow, Leanne K. Casaubon, \\ Howard B. Abrams
}

\begin{abstract}
Background: There is strong evidence that clinical outcomes are improved for stroke patients admitted to specialized Stroke Units. The Toronto Western Hospital (TWH) created a Neurovascular Unit (NVU) using resources from General Internal Medicine, Neurology, and Neurosurgery for patients with stroke and acute neurovascular conditions. Under resource-constrained conditions, the operational and economic impacts of the Neurovascular Unit were unknown. Methods: Retrospective patient-level data was studied from two years prior and one year post NVU implementation. Descriptive statistical analysis and non-parametric testing were conducted on the acute length of stay (LOS), alternate level of care LOS, total cost per bed-day and per visit, and patient flow within each medical service and hospital wide. Results: The median acute LOS per hospitalization for NVU-eligible patients decreased significantly $(\mathrm{p}=0.001$ ). For Neurology patients, mean acute LOS decreased from 9.1 days pre-Neurovascular Unit to 7.6 days post and median acute LOS decreased from 6 to 5 days $(p=0.002)$; however, mean alternate level of care LOS per visit more than doubled (from 1.6 to 4.1 days, $p=0.001$ ). For the Neurology service, the mean cost per visit decreased by $\$ 945$, representing a $5 \%$ reduction $(p=0.042)$ and the mean cost per bed-day decreased by $\$ 233$, or $12.5 \%(\mathrm{p}=0.026)$. Hospital wide, a saving of over $\mathrm{C} \$ 450000$ was achieved. Conclusions: During the first year of operation, the NVU at TWH achieved decreased acute LOS per visit and lowered the total hospitalization cost per year for NVU-eligible patients. Addressing the issue of increased alternate level of care LOS could result in additional efficiencies.
\end{abstract}

RÉSUMÉ: L'impact opérationnel et économique d'une unité de soins neurovasculaires dans un hôpital universitaire de soins aigus. Contexte : Il existe des données importantes démontrant que les résultats cliniques sont améliorés chez les patients atteints d'un accident vasculaire cérébral (AVC) hospitalisés dans une unité de soins spécialisés dans le traitement de l'AVC. Le Toronto Western Hospital (TWH) a établi une unité de soins neurovasculaires (UNV) ayant recours aux ressources de la médecine interne générale, de la neurologie et de la neurochirurgie pour les patients atteints d'un AVC et de troubles neurovasculaires aigus. Dans un contexte de contraintes budgétaires, les impacts opérationnels et économiques de l'unité de soins neurovasculaires n'étaient pas connus. Méthode : Les données rétrospectives des patients ont été étudiées sur une période de 2 ans avant et de 1 an après la création de l'UNV. Nous avons effectué des analyses statistiques descriptives et des tests non paramétriques des données concernant la durée de séjour (DS) en soins aigus, la durée de séjour dans une unité d'un autre niveau de soins, le coût total par jour et par visite ainsi que l'aiguillage des patients dans chaque service médical et dans l'hôpital en général. Résultats : La DS médiane aiguë par hospitalisation pour les patients éligible à l'UNV a diminué significativement ( $\mathrm{p}=0,001)$. Pour les patients de neurologie, la DS moyenne en soins aigus a diminué et est passée de 9,1 jours avant la création de l'unité de soins neurovasculaires à 7,6 jours après sa création et la DS médiane en soins aigus a diminuée de 6 à 5 jours $(\mathrm{p}=0,002)$. Cependant, la DS moyenne par visite dans une unité d'un autre niveau de soins a plus que doublé (de 1,6 jour à 4,1 jours, $\mathrm{p}=0,001$ ). Pour le service de neurologie, le coût moyen par visite a diminué de $945 \$$, ce qui représente une diminution de $5 \%(\mathrm{p}=0,042)$ et le coût moyen par jour a diminué de $233 \$$ soit une diminution de $12,5 \%(\mathrm{p}=0,026)$. Pour tout l'hôpital, ceci représente une épargne de $450000 \$ C$. Conclusions : Au cours de la première année d'opération, l'UNV du TWH a réussi à diminuer la DS aiguë par visite et à diminuer le coût total d'hospitalisation par année pour les patients éligible à l'hospitalisation à l'UNV. Le fait d'examiner la question de la DS dans une unité de soins spécialisés est susceptible d'accroître l'efficience opérationnelle.

Keywords: Canadian study, economic impact, hospital length of stay, neurovascular unit, operational impact, patient flow, stroke unit doi:10.1017/cjn.2015.32

Can J Neurol Sci. 2015; 42: 292-298

\section{STROKE UnITS}

The management of stroke patients in specialized stroke units (SUs) has been shown to be effective for all stroke subtypes in reducing mortality and post-discharge dependency. ${ }^{1-7}$ A systematic review of 19 randomized controlled trials by the Stroke Unit Trialists' Collaboration ${ }^{5}$ found that SU care, typically when SUs were housed in geographically discrete wards, were associated with
From the Centre for Innovation in Complex Care (EA, SH-G, HBA); University Health Network (LKC, HBA); University of Toronto (LKC, HBA), Toronto, ON, Canada; Department of Surgery (EC), Johns Hopkins University, USA.

Received July 6, 2014. Final Revisions Submitted December 5, 2014.

Correspondence to: Eva Appel, University Health Network - Centre for Innovation in Complex Care, Toronto General Hospital, 200 Elizabeth Street, Toronto, Ontario, M5G 2C4, Canada. E-mail: Eva.Appel@uhn.ca 
improved outcomes including reduction in death, dependency, and institutionalization. Research has shown that stroke patients who receive appropriate interventions in a timely fashion have better outcomes ${ }^{8}$ and Lahr et al. ${ }^{9}$ found that an increased number of stroke patients received the recommended interventions when treated at a centralized SU. The Clinical Effectiveness \& Evaluation Unit at the Royal College of Physicians of London created a set of standards for evaluating SUs. One key indicator included in the standards is whether or not stroke patients were treated for at least $90 \%$ of their hospital stay in the SU, as opposed to other inpatient wards, such as General Internal Medicine (GIM). ${ }^{10}$

In 2009, the Canadian Stroke Network published best practice recommendations for the implementation of a SU, highlighting the ideal ratio of resources (e.g. beds, nurses, rehabilitation specialists) to patients, summarized from published ratios based on implementations of SUs. ${ }^{11}$ Other countries and organizations have also published guidelines for implementing SUs; ${ }^{12-14}$ however, there is little guidance on how to implement a SU while considering the overall effects to the hospital, in particular patient flow in related units that typically cared for stroke patients before the introduction of the SU. In particular, there is no guidance on allocating existing bed resources to create a SU.

In light of improved outcomes for care provided in a SU, many centres have centralized stroke care in SUs. In Toronto, Ontario, Canada, three stroke regions were developed to coordinate stroke care; each with a regional stroke centre that was allocated resources to optimize stroke care, including resources to develop a SU. ${ }^{15}$ In September 2011, the Toronto Western Hospital (TWH), an acute care academic hospital and regional stroke centre for the Toronto West Stroke Network created a Neurovascular Unit (NVU) to care for patients with stroke and other acute neurovascular conditions.

\section{The Neurovascular Unit at Toronto Western Hospital}

In comparison with patients with ischaemic stroke and intracerebral hemorrhage that were traditionally included in care models for SUs, patients with acute neurovascular conditions, such as subarachnoid hemorrhage from aneurysms or vascular malformations, often require similar inpatient care plans, including specialized nursing care. Additionally, patients with acute neurovascular conditions may follow the same care path into stroke rehabilitation. For the NVU, TWH expanded the scope of care of a typical SU and included these patients as eligible. The NVU is inter-professionally staffed and has a dedicated team including neurologists with expertise in stroke care, vascular neurosurgeons, nurse practitioners, nurses, and allied health professionals. The NVU team follows best practices for stroke care and aims to transition patients to stroke rehabilitation on an expedited basis. Eligibility for admission to the NVU is determined by a patient's presenting condition being stroke or an acute neurovascular condition which is coded using a predetermined list of ICD-10 codes (See Appendix 1). For patients with eligible codes, exclusion criteria for admission to the NVU were patients with severe pre-morbid disability, patients previously deemed palliative, or patients where the initial diagnosis was not clearly a neurovascular condition. All patients with a study-eligible ICD-10 code final diagnosis at TWH during the study time frame were included, regardless of where they were admitted pre- and post-NVU implementation.

Prior to the implementation of the NVU, stroke patients were typically cared for on the GIM, Neurology, or Neurosurgery nursing units. The TWH had a mobile stroke team, i.e. a team of health care providers with dedicated stroke training that consulted on stroke patients on these nursing units. The NVU was created by studying the resource utilization and flow of stroke and neurovascular patients within these nursing units during this earlier time period and then re-allocating resources. The NVU was also created with the intent to care for stroke patients from multiple hospitals. In order to create the NVU, each involved service (GIM, Neurology, and Neurosurgery) contributed resources based on historic census levels of patients with acute stroke or neurovascular injury. In particular, ten beds were provided by GIM and five each by Neurology and Neurosurgery. As a result, the NVU was created with 20 beds, as a geographicallyisolated Stroke Unit. In the NVU, the most responsible physician (MRP) for admitted NVU patients was either a stroke neurologist from the Neurology service or a vascular neurosurgeon from the Neurosurgery service. The NVU model also includes dedicated staff with stroke expertise (nursing manager, bedside nursing staff, stroke nurse practitioners, allied health staff, a social worker, and a pharmacist).

As part of the NVU, and situated in the same geographic location, TWH has also developed a novel TIA And Minor Stroke (TAMS) Unit. Patients presenting to the emergency department with a transient ischemic attack (TIA) or minor (non-disabling) stroke are urgently evaluated in the TAMS Unit either the same day or the following business day. Evaluation of the TAMS Unit care model is ongoing and will be reported separately.

We conducted an analysis to determine the operational impact of the NVU during its first year. In particular, we compared inpatient visits of NVU-eligible patients before and after the opening of the NVU to study the effect on inpatient hospital length of stay (LOS), patient flow, and cost.

\section{Methods \\ Data Sources}

This was a retrospective analysis of NVU-eligible patients from two years prior to the implementation of the NVU at TWH through one year post-implementation. Any nursing units in the hospital that treated NVU-eligible patients were considered in the analysis.

The study used patient-level data from University Health Network case-costing database and from the Enterprise Data Warehouse (EDW). All inpatient admissions to the TWH with principal ICD-10 diagnostic code deemed as NVU-eligible (see Appendix 1), with costing information available and with admission dates starting January 1, 2010 and discharge dates on or before October 30, 2012 were considered for analysis; these patients were grouped by the MRP from three main services: (1) GIM, (2) Neurology, and (3) Neurosurgery. In addition, a small proportion $(8 \%)$ of patients with ICD-10 stroke and neurovascular codes was admitted to MRPs from several other services (Anesthesiology, Cardiology, Diagnostic Radiology, Endocrinology and Metabolism, Family Practice, Gastroenterology, Plastic Surgery, Respirology, and Rheumatology). The visits assigned to these 'other' services did not significantly affect any of the overall statistics related to patient flow or hospitalization cost and were excluded from the analysis, which focused on changes in the three main services (GIM, Neurology, Neurosurgery). Single visits with an admission date pre-NVU (before September 6, 2011) and discharge 
date post-NVU (on or after September 6, 2011) were excluded from the analysis, as they could not be categorized as being either preNVU or post-NVU implementation.

\section{Data Analysis}

Visits of NVU-eligible patients were grouped in two groups: (1) pre- and (2) post-NVU opening date. Output measures for patient flow, LOS, and cost were assigned to calendar periods (months, quarters, and years) according to visit discharge date. Descriptive statistics, chi-square test and median, Mann-Whitney or Kruskal-Wallis nonparametric tests for two independent samples were performed using IBM-SPSS Statistics 22 package, to compare the variables pre- and post-NVU.

Patient flow was measured in two ways: (1) by looking at the service of the MRP for each visit and then measuring the change in the percentage of patients treated by a given service, and (2) by looking at the discharge nursing unit for each visit and measuring the change in the percentage of patients who were treated in each unit and how many patients were treated in the NVU post-implementation.

To measure length of stay we studied the acute length of stay (ALOS) per visit, the alternate level of care (ALC) LOS per visit, and the total LOS (acute and ALC together) per visit. The ALC designation is given to patients who no longer require acute care but for system reasons are not able to leave acute care. Patients who have been designated ALC are cared for in both acute and post-acute settings and are awaiting transfer to the most appropriate care setting.

Analysis of costs included cost per visit, cost per bed-day, and yearly total cost. Costs included both direct and indirect costs. Cost per bed-day was calculated by dividing the sum of costs for all visits in each month by the sum of LOS (days) of all visits in that month. Yearly costs were prorated from the actual number of months to 12 months. Cost was expressed in 2012 Canadian dollars. Costs that occurred in 2010 and 2011 were adjusted according to Statistics Canada consumer price index, health and personal care for Ontario. For visits crossing calendar years, the price index for each year was applied only to the parts occurring in the corresponding calendar year.

Where inconsistencies were found regarding the nursing unit or service for the same visit (when cross-checking different data sets, e.g. case-costing vs. EDW) the hospital site allocated to each visit was individually verified and corrected by analyzing details of the visit (e.g. Functional Case Costing (FCC) level visits and sub-segments provided with EDW).

\section{RESULTS \\ Patient Flow}

In the 20 months prior to NVU implementation (Jan 1, 2010 through Sept 5, 2011) there were 1096 NVU-eligible visits at TWH assigned to MRPs from GIM, Neurology and Neurosurgery; and in the 14 months post-NVU implementation (Sept 6, 2011 through Oct 31,2012 ) there were 726 visits (Table 1). There were 113 visits pre-NVU and 41 visits post-NVU assigned to MRPs from other services; these visits were excluded. There were 25 visits crossing over the NVU opening date that were also excluded.

Discharge nursing units were grouped into GIM, NVU, Neurology and Neurosurgery, Emergency Department, Intensive Care Unit, and Other.

After the NVU implementation, there was a decline in the number of patients assigned to MRPs from the GIM service (from $29.4 \%$ of all patients pre-NVU, to $4.8 \%$ post-NVU, $\mathrm{p}<0.0001$ ), and at the same time there was an increase in the number of patients assigned to Neurology MRPs (from 20.3\% of all patients pre-NVU, to $49.2 \%$ post-NVU, $\mathrm{p}<0.0001$ ). The proportion of patients assigned to Neurosurgery MRPs remained relatively constant, $50.3 \%$ pre-NVU and $46.0 \%$ post-NVU (Table 1 ).

With the exception of TIA patients, the overall distributions of diagnoses for NVU-eligible patients pre- and post-NVU were similar, with no significant difference. The percentage of TIA patients decreased from $8.0 \%$ of all patients pre-NVU to $4.4 \%$ post-NVU (Table 2).

In our analysis of the discharge locations for NVU-eligible patients, we found a decrease in the percentage of patients in the GIM nursing units from $28.4 \%$ of all patients pre-NVU to $3.7 \%$ post-NVU, or as yearly prorated counts - from 185 down to 23 . Additionally, after its opening, the majority of NVU-eligible patients $(71.5 \%)$ were treated in the NVU (Figure 1).

\section{Length of Stay}

The mean number of acute care days per visit for NVU-eligible patients decreased post-NVU. For GIM, the mean ALOS decreased by $18.4 \%$, from 8.2 days pre-NVU to 6.7 days postNVU, for Neurology by $16.5 \%$, from 9.1 to 7.6 days per visit, and for Neurosurgery by $5.9 \%$, from 9.9 days to 9.3 days (Table 3 , Table 4). Hospital-wide, the number of acute days per visit for NVU-eligible patients admitted to those services decreased by $9.6 \%$, from 9.2 days pre-NVU to 8.3 days post-NVU (Table 4). The decrease in the median values of acute LOS per visit by

Table 1: Visits by MRP's Service pre-NVU versus post-NVU

\begin{tabular}{l|c|c|c|c|c|c}
\hline & \multicolumn{3}{|c|}{ Pre-NVU } & & Post-NVU \\
\hline Service & Number of visits & Percent of visits (\%) & $\begin{array}{c}\text { Number of visits } \\
\text { pro-rated to one year }\end{array}$ & Number of visits & Percent of visits (\%) & $\begin{array}{c}\text { Number of visits } \\
\text { pro-rated to one year }\end{array}$ \\
\hline GIM & 322 & 29.4 & 191.7 & 35 & 4.8 & \\
\hline Neurology & 223 & 20.3 & 132.8 & 357 & 49.3 & 308.8 \\
\hline Neurosurgery & 551 & 50.3 & 328.1 & 334 & 46.0 & \\
\hline Total & 1096 & 100.0 & 652.6 & 726 & 100.0 & 288.9 \\
\hline
\end{tabular}

GIM: general internal medicine

Note: The $\chi^{2}$ value is 190.3474 , showing with a high probability $(\mathrm{p}<0.05)$ that the variability in patients assigned to specific services post-NVU versus pre NVU was not due to random chance. 
Table 2: Visits by Final Diagnosis pre-NVU versus post-NVU

\begin{tabular}{l|c|c|c|c|c|c}
\hline & \multicolumn{3}{|c|}{ Pre-NVU } & \multicolumn{3}{c}{ Post-NVU } \\
\hline Final Diagnosis & $\begin{array}{c}\text { Number of } \\
\text { visits }\end{array}$ & $\begin{array}{c}\text { Percent of } \\
\text { visits (\%) }\end{array}$ & $\begin{array}{c}\text { Number of visits } \\
\text { pro-rated to one year }\end{array}$ & $\begin{array}{c}\text { Number of } \\
\text { visits }\end{array}$ & $\begin{array}{c}\text { Percent of } \\
\text { visits (\%) }\end{array}$ & $\begin{array}{c}\text { Number of visits } \\
\text { pro-rated to one year }\end{array}$ \\
\hline Acute Neurovascular Condition (NV) & 314 & 28.6 & 187.0 & 209 & 28.8 & 180.8 \\
\hline Acute Ischemic Stroke (AIS) & 382 & 34.8 & 227.5 & 296 & 40.8 & 256.0 \\
\hline Intracerebral Hemorrhage (ICH) & 152 & 13.9 & 90.5 & 103 & 14.2 & 89.1 \\
\hline Subarachnoid Hemorrhage (SAH) & 160 & 14.6 & 95.3 & 86 & 11.8 & 74.4 \\
\hline Transient Ischemic Attack (TIA) & 88 & 8.0 & 52.4 & 32 & 4.4 & 27.7 \\
\hline Total & 1096 & 100.0 & 652.6 & 726 & 100.0 & 627.9 \\
\hline
\end{tabular}

Note: The $\chi^{2}$ value excluding TIA is 4.3327 , thus the distributions are not different at $10 \%$ sig. level

service follows the decrease seen in their mean values (Table 3). For the Neurology service, the change in median ALOS was statistically significant (from 6.0 to 5.0 days, $\mathrm{p}=0.002$ ).

Of the total number of visits, the proportions of visits with acute days only $(\mathrm{ALC}=0)$ were similar, $74 \%$ pre-NVU and $70 \%$ post-NVU, with no statistical significance to changes in the distribution of monthly visits.

For visits with ALC $>0$, the mean number of ALC days per visit increased across all services. For GIM, there was an increase in ALC days of $61 \%$ (from 9.6 to 15.4 days), for Neurology by $75 \%$ (from 5.4 to 9.5 days) and for Neurosurgery by $6.2 \%$ (from 10.9 to 11.6 days).

The median values for total LOS per visit decreased across all services post-NVU: for GIM from six to five days, for Neurology from seven to six, and for Neurosurgery from six to four. The mean values of total LOS also decreased, with the exception of Neurology where the mean total LOS per visit increased by one day (from 10.7 days pre- NVU to 11.7 post-NVU).

\section{Cost}

Comparing the 20 months pre-NVU and 14 months post-NVU, there was a hospital-wide decrease in the total yearly cost of caring for NVU-eligible patients admitted at TWH to the GIM, Neurology, and Neurosurgery services, from \$15 663245 pro-rated per

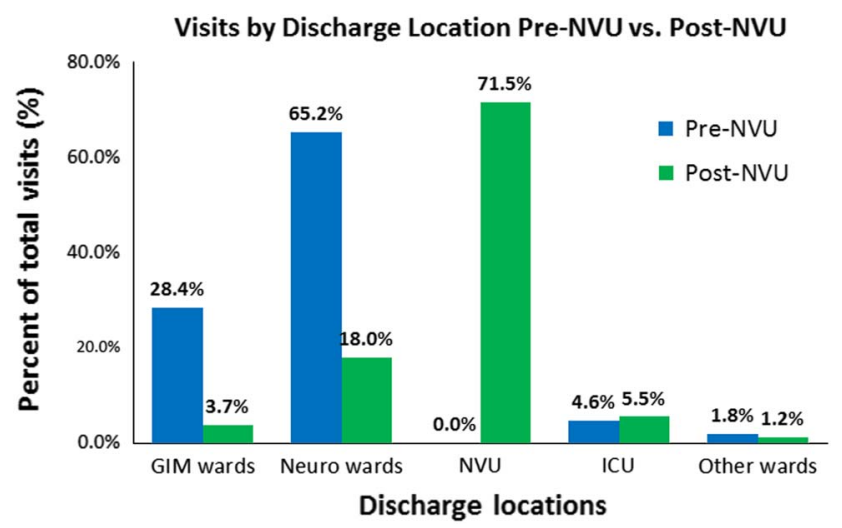

Figure 1: Distribution of patients by nursing unit before and after the opening of the $N V U$. year pre-NVU to $\$ 15160834$ post-NVU, representing a yearly savings of over $\$ 450000$ (Table 5).

The mean cost per visit decreased post-NVU in all services. In GIM there was a decrease of $17.3 \%(\mathrm{p}=0.087)$, in Neurology of $4.7 \%(\mathrm{p}=0.042)$ and in Neurosurgery of $4.0 \%(\mathrm{p}=0.091)$ (Table 4).

The mean cost per bed-day decreased by $9.4 \%$ (from $\$ 1073$ to $\$ 972$, not statistically significant at $5 \%$ ) for patients treated in the GIM service and by $12.5 \%$ (from $\$ 1861$ to $\$ 1628, \mathrm{p}=0.027$ ) for the Neurology service.

\section{Discussion}

\section{Overall Findings and Implications}

The creation of the NVU at the Toronto Western Hospital resulted in operational redirection of NVU-eligible patients from the GIM service to the Neurology service.

In the first year of operation, the NVU cared for the majority of NVU-eligible patients $(71.5 \%)$ at TWH. Additionally, for NVUeligible patients treated after the NVU under the Neurology service, there were statistically significant reductions in ALOS per visit, cost per visit, and cost per bed-day. However, the data revealed a statistically significant increase in ALC LOS for NVU-eligible patients treated by Neurology after the opening of the NVU. Our study showed that the TWH has improved the efficiencies of care in the NVU compared to pre-NVU so that patients are ready for the next level of care sooner. Thus, the increase in ALC LOS may have been a consequence of the shorter ALOS achieved with improved organized care provided by the specialized inter-professional care team of the NVU to patients whose discharge destination was still long-term care. The ALC designation for patients in acute care hospitals provides information to policy makers/governments and this, in turn, is informing the system changes in rehabilitation, community resources, and long term care/complex continuing care. The increased ALC LOS reflects an ongoing need for system improvements in rehabilitation and other community services, as well as long term care/complex continuing care beds, so that when patients are ready to leave acute care they have immediate access to the next level of care. In order for the hospital to realize the full potential benefits of the NVU on cost and total LOS, any challenges in transitioning patients out of the hospital must be addressed. These elements of the system are now the focus of policy makers/ government in Ontario so that hopefully the gains in decreased acute 
Table 3: Acute LOS, ALC and Total LOS by MRP's service, pre-NVU versus post-NVU

\begin{tabular}{|c|c|c|c|c|c|c|c|c|c|}
\hline \multirow[b]{2}{*}{ Service } & & \multicolumn{4}{|c|}{ Pre-NVU } & \multicolumn{4}{|c|}{ Post-NVU } \\
\hline & & $\begin{array}{c}\text { Number of } \\
\text { visits }\end{array}$ & $\begin{array}{c}\text { Acute LOS } \\
\text { (days) }\end{array}$ & $\begin{array}{c}\text { ALC } \\
\text { (days) }\end{array}$ & $\begin{array}{c}\text { Total LOS } \\
\text { (days) }\end{array}$ & $\begin{array}{c}\text { Number of } \\
\text { visits }\end{array}$ & $\begin{array}{l}\text { Acute LOS } \\
\text { (days) }\end{array}$ & $\begin{array}{c}\text { ALC } \\
\text { (days) }\end{array}$ & $\begin{array}{c}\text { Total LOS } \\
\text { (days) }\end{array}$ \\
\hline \multirow[t]{4}{*}{ GIM } & Mean & 322 & 8.23 & 3.48 & 11.71 & 35 & 6.71 & 3.97 & 10.69 \\
\hline & Std. Deviation & & 9.504 & 10.284 & 15.316 & & 5.399 & 14.366 & 16.558 \\
\hline & Median & & 5.0 & 0.0 & 6.0 & & 5.0 & 0.0 & 5.0 \\
\hline & Interquartile Range & & $3.0-10.0$ & $0-3.0$ & $3.0-14.0$ & & $2.0-9.0$ & $0-1.0$ & $3.0-10.0$ \\
\hline \multirow[t]{4}{*}{ Neurology } & Mean & 223 & 9.15 & 1.61 & 10.76 & 357 & 7.64 & 4.08 & 11.72 \\
\hline & Std. Deviation & & 11.526 & 3.671 & 13.312 & & 9.489 & 10.635 & 17.214 \\
\hline & Median & & 6.0 & 0.0 & 7.0 & & $5.0^{*}$ & $0.0^{\dagger}$ & 6.0 \\
\hline & Interquartile Range & & $3.0-10.0$ & $0-1.0$ & $3.0-13.0$ & & $3.0-9.0^{*}$ & $0-3.0^{\dagger}$ & $3.5-12.0$ \\
\hline \multirow[t]{4}{*}{ Neurosurgery } & Mean & 551 & 9.86 & 2.01 & 11.86 & 334 & 9.28 & 1.88 & 11.16 \\
\hline & Std. Deviation & & 13.104 & 8.853 & 17.280 & & 12.867 & 8.691 & 17.913 \\
\hline & Median & & 6.0 & 0.0 & 6.0 & & $4.0^{\ddagger}$ & 0.0 & 4.0 \\
\hline & Interquartile Range & & $2.0-14.0$ & $0-0.0$ & $2.0-15.0$ & & $2.0-11.25$ & $0-0.0$ & $2.0-13.0$ \\
\hline
\end{tabular}

GIM = general internal medicine; $\mathrm{Std}=$ standard LOS = length of stay; $\mathrm{ALC}=$ alternative level of care

*Statistically significant difference: for median $p=0.002$ (Median Test), for distribution $p=0.039$ (Mann-Whitney U Test)

${ }^{\dagger}$ Statistically significant difference: for median $p=0.002$ (Median Test), for distribution $p=0.001$ (Mann-Whitney U Test)

${ }^{\ddagger}$ Statistically significant difference: for median $\mathrm{p}=0.042$ (Median Test)

Table 4: Changes in mean LOS and cost by MRP's service post-NVU compared to pre-NVU

\begin{tabular}{l|c|c|c|c|c|c}
\hline & \multicolumn{6}{|c}{ Percent changes between post-NVU vs. pre-NVU $(\boldsymbol{\Delta} \%)$} \\
\hline Service & $\begin{array}{c}\Delta \text { ALOS per visit } \\
(\boldsymbol{\%})\end{array}$ & $\begin{array}{c}\Delta \text { ALC LOS per visit } \\
(\boldsymbol{\%})\end{array}$ & $\begin{array}{c}\Delta \text { Total LOS per visit } \\
(\boldsymbol{\%})\end{array}$ & $\begin{array}{c}\Delta \text { Cost per visit } \\
(\boldsymbol{\%})\end{array}$ & $\begin{array}{c}\Delta \text { Cost per Bed-day } \\
(\boldsymbol{\%})\end{array}$ & $\begin{array}{c}\Delta \text { Total Cost per year (prorated) } \\
(\boldsymbol{\%})\end{array}$ \\
\hline GIM & -18.4 & 14.1 & -8.7 & -17.3 & -9.4 & -86.9 \\
\hline Neurology & -16.5 & 153.3 & 8.9 & -4.7 & -12.5 & 121.6 \\
\hline Neurosurgery & -5.9 & -6.3 & -5.9 & -4.0 & 2.1 & -15 \\
\hline All Services & -9.6 & 29.8 & -1.6 & 0.6 & 2.2 & -3.2 \\
\hline
\end{tabular}

$\mathrm{GIM}=$ general internal medicine; $\mathrm{ALOS}=$ acute length of stay; $\mathrm{LOS}=$ length of stay; $\Delta=$ change

Note: A negative value represents a decrease in LOS or cost.

Table 5: Mean cost (per visit, bed-day, and year) by MRP's service pre-NVU versus post-NVU

\begin{tabular}{l|c|c|c|c|c|c}
\hline & \multicolumn{3}{|c|}{ Pre-NVU } & \multicolumn{3}{c}{ Post-NVU } \\
\hline Service & Cost per visit (\$) & Cost per bed-day (\$) & Cost per year (prorated) (\$) & Cost per visit (\$) & Cost per bed-day (\$) & Cost per year (prorated) (\$) \\
\hline GIM & 12,558 & 1,073 & $2,407,774$ & 10,623 & 972 & \\
\hline Neurology & 20,018 & 1,861 & $2,657,997$ & 19,073 & 1,628 & \\
\hline Neurosurgery & 32,301 & 2,723 & $10,597,474$ & 31,006 & 2,779 & $5,889,227$ \\
\hline All Services & 24,002 & 2,070 & $15,663,245$ & 24,144 & 2,116 & $8,957,239$ \\
\hline
\end{tabular}

$\mathrm{GIM}=$ general internal medicine

LOS in the NVU will reflect true system gains once the community care and rehabilitation have been optimized.

Overall, with the introduction of the NVU, the hospital-wide first year savings was greater than $\$ 450000$ (3.2\% decrease compared to pre-NVU). It should be noted that these are conservative results because of the opening at the same time of the TAMS Unit, an ambulatory care unit for the rapid investigation and treatment of the high risk TIA population (and patients with non-disabling stroke that do not require inpatient rehabilitation); as such there was also a drop of $47 \%$ in the number of TIA patients admitted post-NVU (162 patients were referred to the TAMS Unit in the post-NVU study period). The TAMS Unit costs and analysis were not included in the cost review of the NVU itself. Since TIA patients tend to have shorter LOS and lower costs than other diagnostic groups, if the 
TAMS Unit patients would have been included in the overall results, we would likely have shown an even larger reduction in LOS and cost with the introduction of the NVU.

A limitation of our study is that the data analyzed was extracted from a historical cohort and there may have been biases due to changes in care that we could not account for. For example there have been new policies introduced after opening of the NVU, such as the "walk-in" code stroke protocols, which caused an increase in the tissue plasminogen activator (tPA) rates. Previous studies have shown that tPA-treated patients have a shorter average length of stay; therefore it was conceivable that if we were giving more tPA post-NVU then this might have been a factor in decrease of LOS. However, even though the rates of tPA increased over time, our data did not show any significant correlation between the tPA treatment and each of acute LOS, ALC LOS and total LOS (measured using the Pearson correlation coefficient) pre-and postNVU. This strengthens the conclusion that the NVU had the most significant impact on the decrease of acute LOS.

Another limitation of our study is that we could not collect and analyze other factors that could have influenced the length of stay, for example the incidence of some infections, blood sugars and severity of strokes between the two groups. However, we analyzed the rates of pneumonia acquired by patients in our cohorts before and after NVU. As expected, the ALOS was strongly correlated with the pneumonia indicator $(\mathrm{p}<0.001)$; but since the distribution of incidents of pneumonia was the same in the preand post-NVU cohorts, this was not a factor affecting the difference between acute LOS pre- versus post-NVU.

\section{Future Research}

Based on the findings of this analysis, future research is warranted in the following areas:

(1) To understand the factors associated with the cost per bed-day decrease with the introduction of the NVU.

(2) To fully understand the interaction and combined effects of the NVU and TAMS Unit.

(3) To distinguish between the cost per acute hospital day and the cost per ALC day.

(4) A cost-effectiveness analysis combining the economic impact of this study with the clinical outcomes measures (ongoing study) is required to confirm whether the NVU is at least cost-effective, or even a dominant strategy.

\section{CONCLUSIONS}

During the first year of operation, the NVU at TWH achieved decreased acute LOS per visit and lowered the total hospitalization cost per year for NVU-eligible patients. For the NVU to attain greater efficiencies, the issue of increased ALC LOS and transition to the next appropriate level of care needs to be addressed. Finally, the results of the ongoing study on clinical outcomes are essential to determine whether the NVU provides the expected improvement in clinical outcomes, and if so, whether it is a costeffective strategy.

\section{FUNDING}

The authors would like to acknowledge the financial support of the University Health Network, and the program groups of Medical and Community Care, and the Toronto Western Hospital Neurovascular Unit Fund.

\section{DisCLOSURES}

None.

\section{REFERENCES}

1. Fjaertoft H, Rohweder G, Indredavik B. Stroke Unit Care Combined with Early Supported Discharge Improves 5-Year Outcome. Stroke. 2011;42:1707-11.

2. Evans A, Perez I, Harraf F, et al. Can Differences in Management Processes Explain Different Outcomes. Lancet. 2001;358: 1586-1592.

3. Rotter T, Kinsman L, James E, et al. The Effects of Clinical Pathways on Professional Practice, Patient Outcomes, Length of Stay, and Hospital Costs. Eval Health Prof. 2012;35:3-27.

4. Cereda CW, Stadler C, Andreotti J, et al. Impact of Implementation of a New Semi-Intensive Stroke Unit versus a Mobile Stroke Team System - A Prospective Study within the Neurocentro of Southern Switzerland. Clin Neurophysiol. 2012;123:e101.

5. Stroke Unit Trialists' Collaboration. Collaborative Systematic Review of the Randomized Trials of Organized Inpatient (Stroke Unit) Care after Stroke. BMJ. 1997;314:1151-9.

6. Chen LK, McClaran J, Buchan AM. Impact of Acute Stroke on Hospital Length of Stay. Arch Gerontol Geriatr. 2009;49.1:e12-5.

7. Kapral MK, Silver FL, Hall R, Stamplecoski M, O'Callaghan C, Tu JV. Effect of a Provincial System of Stroke Care Delivery on Stroke Care Outcomes. CMAJ. 2013;185:e483-91.

8. Addo J, Crichton S, Bhalla A, Rudd AG, Wolfe CDA. Impact of Implementation of Evidence-Based Acute Stroke Interventions on Survival: The South London Stroke Register. PLoS. 2013;8: e61581.

9. Lahr M, Luijckx GJ, Vroomen P, van der Zee DJ, Buskens E. Proportion of Patients Treated with Thrombolysis in a Centralized versus Decentralized Acute Stroke Care Setting. Stroke. 2012;43:1336-40.

10. Hoffman A, Wurie F, Grant R, Lowe D, Rudd A. National sentinel stroke audit phase 2 (clinical audit) 2008. Royal College of Physicians of London. 2009:17-33.

11. Canadian Stroke Network. A Guide to the Implementation of Stroke Unit Care. The Canadian Stroke Strategy; 2009.

12. National Collaborating Centre for Chronic Conditions. Stroke Guideline for Diagnosis and Management of Acute Stroke and TIA. Royal College of Physicians; 2012.

13. Intercollegiate Stroke Working Party. National clinical guideline for stroke, 4th edition. London: Royal College of Physicians; 2012.

14. Jauch EC, Saver JL, Adams HP, et al. Guidelines for the Early Management of Patients with Acute Ischemic Stroke. Stroke. 2013;44:870-947.

15. Implementing Stroke and Orthopaedic Best Practices in the Toronto Central LHIN: Analysis of System Wide Impacts. Hay Group. March 31, 2012. 


\section{APPENDIX 1 - ICD10 CODES DEFINING NVU-ELIGIBILITY}

For the purposes of this study, NVU-eligible patients were divided into two patient types - stroke and acute neurovascular conditions (NV). Classifications were made by grouping the ICD-10 codes as defined by the hospital.

\begin{tabular}{l|c|c}
\hline Description & Code & Patient Type \\
\hline Benign neoplasm of carotid body & D35.5 & NV \\
\hline Vascular myelopathies & G95.1 & NV \\
\hline Retinal artery and vascular occlusion (excluding H34.1 below) & H34.(0,2,8,9) & NV \\
\hline Other Subarachnoid Hemorrhage (SAH) & I60.8 & NV \\
\hline Cerebral infarction due to cerebral venous thrombosis & I63.6 & NV \\
\hline Arterial occlusion/stenosis & I67 & NV \\
\hline Other cerebrovascular diseases & I69 & NV \\
\hline Sequelae of cerebrovascular disease & Q28.(0,1,2,3) & NV \\
\hline Arteriovenous and other malformations of precerebral and cerebral vessels & G45 & NV \\
\hline Transient Ischemic Attack & I60 & Stroke \\
\hline Subarachnoid Hemorrhage & I61 & Stroke \\
\hline Intracerebral Hemorrhage & I63 & Stroke \\
\hline Ischemic Stroke & I64 & Stroke \\
\hline Acute Stroke - unspecified & H34.1 & Stroke \\
\hline Central Retinal Artery Occlusion & Stroke \\
\hline
\end{tabular}

Sub-codes appearing in the NV classification whose parent code appears in the stroke classification are part of NV (e.g. I63.6 [NV] vs. I63 [Stroke]). All other sub-codes not mentioned, are part of the stroke classification (e.g. I63.0, I63.1). 